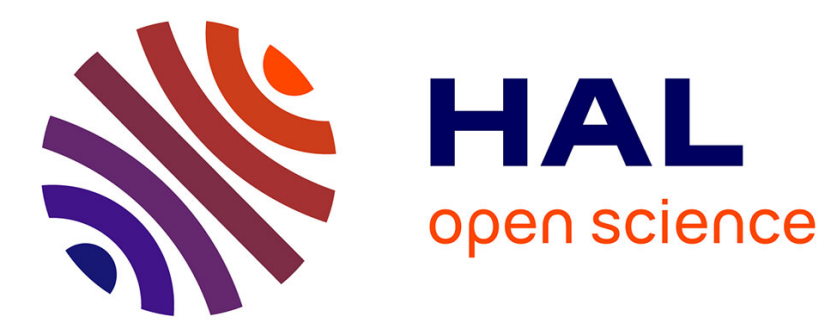

\title{
X-Ray Absorption Study of the Short Range Order of Tungsten and Molybdenum Ions in BaO-P2O5-WO3 and CaO-P2O5-MoO3 Glasses
}

\author{
A. Kuzmin, J. Purans
}

\section{- To cite this version:}

A. Kuzmin, J. Purans. X-Ray Absorption Study of the Short Range Order of Tungsten and Molybdenum Ions in $\mathrm{BaO}-\mathrm{P} 2 \mathrm{O} 5-\mathrm{WO} 3$ and CaO-P2O5-MoO3 Glasses. Journal de Physique IV Proceedings, 1997, 7 (C2), pp.C2-971-C2-973. 10.1051/jp4:19972105 • jpa-00255162

HAL Id: jpa-00255162

https://hal.science/jpa-00255162

Submitted on 1 Jan 1997

HAL is a multi-disciplinary open access archive for the deposit and dissemination of scientific research documents, whether they are published or not. The documents may come from teaching and research institutions in France or abroad, or from public or private research centers.
L'archive ouverte pluridisciplinaire HAL, est destinée au dépôt et à la diffusion de documents scientifiques de niveau recherche, publiés ou non, émanant des établissements d'enseignement et de recherche français ou étrangers, des laboratoires publics ou privés. 


\title{
X-Ray Absorption Study of the Short Range Order of Tungsten and Molybdenum Ions in $\mathrm{BaO}_{2} \mathrm{P}_{2} \mathrm{O}_{5}-\mathrm{WO}_{3}$ and $\mathrm{CaO}-\mathrm{P}_{2} \mathrm{O}_{5}-\mathrm{MoO}_{3}$ Glasses
}

\author{
A. Kuzmin and J. Purans \\ Institute of Solid State Physics, 8 Kengaraga str., 1063 Riga, Latvia
}

\begin{abstract}
The analysis of XANES and EXAFS in BaO- $\mathrm{P}_{2} \mathrm{O}_{5}-\mathrm{WO}_{3}$ and $\mathrm{CaO}-\mathrm{P}_{2} \mathrm{O}_{5}-\mathrm{MoO}_{3}$ glasses at the $\mathrm{W} \mathrm{L}_{1,3}$ and Mo $\mathrm{K}$ edges was performed in comparison with a number of crystalline $\mathrm{WO}_{3}, \mathrm{CaWO}_{4}, \mathrm{Na}_{0.66} \mathrm{WO}_{3}, \alpha-\mathrm{MoO}_{3}, \beta-\mathrm{MoO}_{3}$ and amorphous a- $\mathrm{WO}_{3}$, $\mathrm{a}-\mathrm{MoO}_{3}$ compounds. The results of the EXAFS modelling by two different methods ((1) multi-shell single-scattering model within harmonic approximation and (2) model-independent radial distribution function (RDF) approach) allowed us to extract detailed structural information on the first coordination shell of metal (W or $\mathrm{Mo}$ ) ion. Using the obtained data together with the information given by other experimental techniques, we propose a structural model of the local environment distortion around tungsten and molybdenum ions in phosphate glasses.
\end{abstract}

Tungsten-phosphate and molybdenum-phosphate glasses belong to a group of glasses which incorporate distorted octahedral structural units $\left[\mathrm{MeO}_{6}\right](\mathrm{Me}=\mathrm{W}, \mathrm{Mo})$ within the glass network and whose structure is still not well understood [1-3]. Besides they exhibit interesting electrochromic properties and high ionic conductivity that makes them potential materials for electrooptical applications $[3,4]$. Recent use of the x-ray absorption spectroscopy to study tungsten-phosphate glasses showed possibility to obtain original and complementary to other experimental techniques information on the local environment around tungsten ions [3,4]. In this work we present an accurate EXAFS study of the short range order of tungsten and molybdenum ions in phosphate glasses using conventional multi-shell harmonic approximation and model-independent radial distribution function (RDF) approach, developed recently by one of us [5].

The tungsten-phosphate and molybdenum-phosphate glasses had the following compositions (in mol. \%): $40 \mathrm{BaO}-40$ $\mathrm{P}_{2} \mathrm{O}_{5}-20 \mathrm{WO}_{3}\left(20 \% \mathrm{WO}_{3}\right), 30 \mathrm{BaO}-30 \mathrm{P}_{2} \mathrm{O}_{5}-40 \mathrm{WO}_{3}\left(40 \% \mathrm{WO}_{3}\right), 20 \mathrm{BaO}-20 \mathrm{P}_{2} \mathrm{O}_{5}-60 \mathrm{WO}_{3}\left(60 \% \mathrm{WO}_{3}\right), 34 \mathrm{P}_{2} \mathrm{O}_{5}-66 \mathrm{WO}_{3}$ $\left(66 \% \mathrm{WO}_{3}\right), 45 \mathrm{CaO}-45 \mathrm{P}_{2} \mathrm{O}_{5}-10 \mathrm{MoO}_{3}\left(10 \% \mathrm{MoO}_{3}\right), 40 \mathrm{CaO}-40 \mathrm{P}_{2} \mathrm{O}_{5}-20 \mathrm{MoO}_{3}\left(20 \% \mathrm{MoO}_{3}\right), 30 \mathrm{CaO}^{-30} \mathrm{P}_{2} \mathrm{O}_{5}-40 \mathrm{MoO}_{3}$ $\left(40 \% \mathrm{MoO}_{3}\right)$ and $20 \mathrm{CaO}-20 \mathrm{P}_{2} \mathrm{O}_{5}-60 \mathrm{MoO}_{3}\left(60 \% \mathrm{MoO}_{3}\right)$. A set of reference compounds was also used: polycrystalline powders of $\mathrm{WO}_{3}, \mathrm{Na}_{0.66} \mathrm{WO}_{3}, \mathrm{CaWO}$ and $\alpha-\mathrm{MoO}_{3}$, polycrystalline $\beta-\mathrm{MoO}_{3}$ and amorphous a- $\mathrm{WO}_{3}$ and a-MoO $\mathrm{M}$ thin films.

$\mathrm{X}$-ray absorption spectra (XAS) (Figure 1) of glasses and reference compounds were measured in transmission mode at the $\mathrm{W} \mathrm{L}_{1,3}$ and Mo K edges using a standard setup of the ADONE PWA-BX1 wiggler beam line, equipped with the Si(220) channel-cut crystal monochromator and two ion chambers containing krypton gas, and the LURE DCI EXAFS-3 beam line, equipped with the $\mathrm{Si}(311)$ double-crystal monochromator and two ion chambers containing argon gas, respectively. All measurements were performed at room temperature. The details of the experiments can be found in $[4,6]$.

The XAS were treated by the "EDA" software package [5]. The EXAFS signals were extracted following standard procedure and the contributions from the first shell were singled out by the Fourier filtering (see Figures 2 and 3 ). Thus obtained 1st-shell EXAFS signals were utilised in the best-fit procedure using two different methods: (1) multi-shell singlescattering model within harmonic approximation and (2) model-independent RDF approach [5]. To compare the results of two methods, the model-independent RDF's were decomposed into a set of Gaussian lines whose parameters were found in good agreement with the ones obtained by the first method. Note that the total number of obtained parameters satisfies to the Nyquist criterion and to the Fisher's $F_{0.95 \%}$-test. The details of the data analysis can be found in $[5,6]$.

The XANES signals at the $\mathrm{W} \mathrm{L}_{3}$-edge contain a strong resonance - the so-called "white line" (WL), located just below the continuum threshold $E_{0}$ (Figure 1): it corresponds to the dipole-allowed transition from the $2 p_{3 / 2}(W)$ level into a quasi-bound $5 d(\mathrm{~W})+2 p(\mathrm{O})$ mixed-state. The same final state is probed by the excitation of the $2 s(\mathrm{~W})$ electron at the $\mathrm{L}_{1}$-edge, however, in this case the intensity of the transition depends strongly on the local symmetry and the degree of the $p d$-mixing. The transition is dipole-forbidden in regular octahedron, having an inversion center, but becomes allowed in distorted octahedron $\left(\mathrm{WO}_{3}\right)$ and in tetrahedron $\left(\mathrm{CaWO}_{4}\right)$. Thus, the intensity of the peak (shoulder) below the continuum threshold at the $\mathrm{K}$ or $\mathrm{L}_{1}$ edge allows to estimate roughly the coordination and the degree of distortion in the 1st shell. A comparison of the XANES signals suggests that in glasses, both W and Mo ions are located in strongly distorted octahedral-like coordination.

The qualitative results of the XANES analysis agree well with the quantitative data obtained by EXAFS. The simulation of the first-shell EXAFS signals in $\mathrm{BaO}-\mathrm{P}_{2} \mathrm{O}_{5}-\mathrm{WO}_{3}$ glasses by two methods, mentioned above, suggests that the RDF's around tungsten are composed of two groups of 3 oxygen ions each located at $\sim 1.73$ and $\sim 2.02 \AA$. Note that in $60 \% W \mathrm{O}_{3}$-glass, there 
are octahedra of two types, distorted as $3: 3(\sim 70 \%)$ and $4: 2(\sim 30 \%)$ : the latter distortion is similar to the one in crystalline $\mathrm{WO}_{3}$. Close RDF's were found in $\mathrm{CaO}-\mathrm{P}_{2} \mathrm{O}_{5}-\mathrm{MoO}_{3}$ glasses, however, here the RDF peak of the distant group of oxygen ions is strongly asymmetric with a tail at long distances. As a result, the local surrounding of molybdenum can be approximated by three groups of oxygens consisting of 3,2 and 1 atoms at $\sim 1.68, \sim 1.98$ and $\sim 2.11 \AA$, respectively. Note that in the $66 \% W_{3}$ glass without $\mathrm{BaO}$, the 1st-shell is splitted into two groups of 2 and 4 oxygen ions at $\sim 1.72$ and $\sim 1.95 \AA$. Thus the type of the first-shell distortion in phosphate glasses differs from the one in the reference crystals and amorphous thin films (see Table 1) and can be attributed to the off-centre displacement of $\mathrm{W}$ or Mo ions in the $\langle 111\rangle$ directions. Note that in pure crystalline and amorphous $\mathrm{MeO}_{3}$ compounds, $\mathrm{W}$ or $\mathrm{Mo}$ ions are displaced off-centre in the $\langle 110\rangle$ directions (Table 1$)$.

The degree of the $\left[\mathrm{MeO}_{6}\right]$ distortion $\Delta$ was estimated using the formula $\Delta=\langle|\mathrm{R}-\langle\mathrm{R}\rangle|\rangle[6,7]$ from the RDF's, determined by the method 2. The error of $\Delta$ is about $\pm 0.001 \AA$ : it is related to the uncertainty of the shape of the RDF. Note that in the glasses, $\Delta$ decreases with increasing $\mathrm{MeO}_{3}$ content (Figure 4(a)) that is attributed to a decrease of the number of long $\mathrm{Me}-\mathrm{OPO}_{3}$ bonds, and, besides, $\Delta$ is larger in the molybdenum glasses and oxides (Figure 4(a) and Table 1). In tungsten containing reference compounds, the values of $\Delta$ agree with the ones from diffraction studies [7] and correlate with the valence state of tungsten ions: this dependence allows to estimate the valency of $W$ in glasses (Figure 4(b)). The obtained results suggest that in spite of a signal from the $\mathrm{W}^{5+} d^{1}$ - ions has been detected by electron paramagnetic resonance (EPR) spectroscopy [8] in these glasses, the total amount of $\mathrm{W}^{5+}$ ions is too small to be detectable in the EXAFS signal.
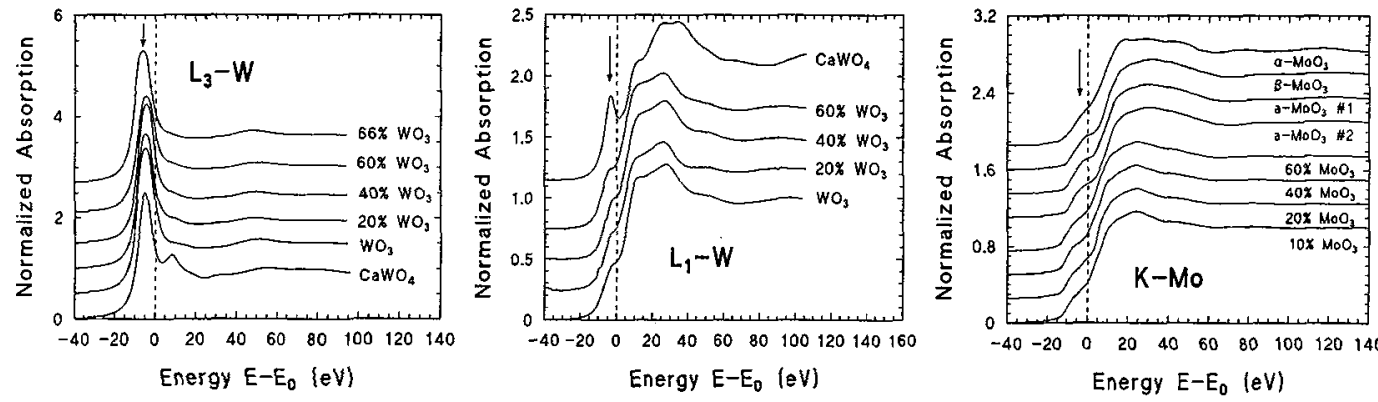

Figure 1: XANES signals at the $\mathrm{W} \mathrm{L}_{1,3}$ and $M o \mathrm{~K}$ edges in glasses and reference compounds. The positions of the WL's are indicated by arrows. Note the increase of the shoulder intensity at the $\mathrm{L}_{1}$ and $\mathrm{K}$ edges with increasing [MeO $\mathrm{M}_{6}$ ] distortion.
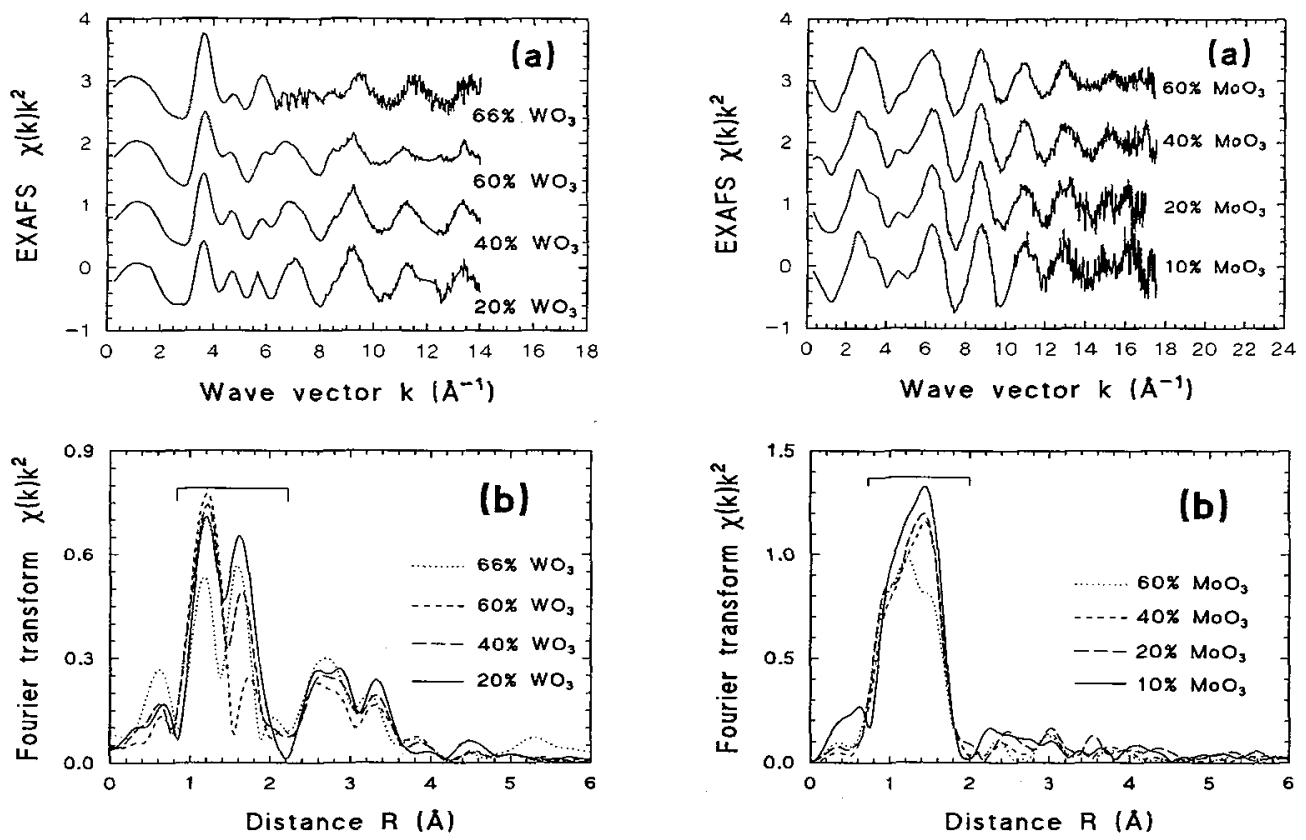

Figure 2: EXAFS signals and their FT'S at the $\mathrm{W} \mathrm{L}_{3}$-edge. The region of the first shell is indicated by solid bracket.

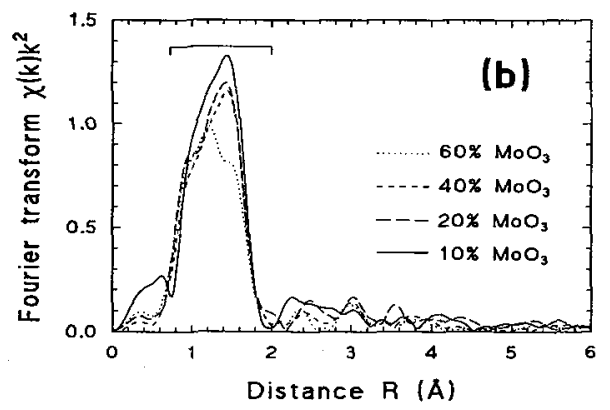

Figure 3: EXAFS signals and their FT's at the Mo K-edge. The region of the first shell is indicated by solid bracket. 

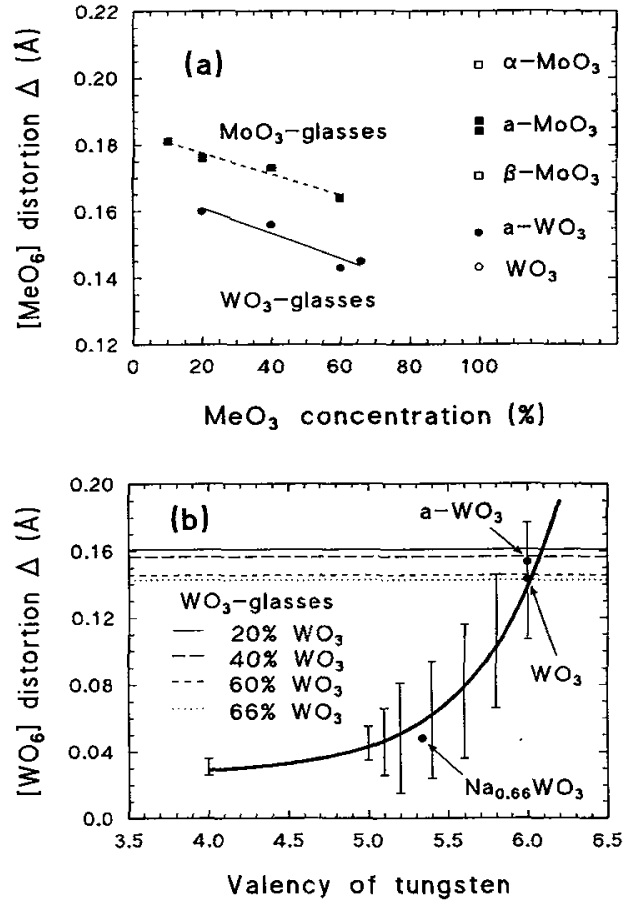

Figure 4: (a) Distortion $\Delta$ of the $\left[\mathrm{MeO}_{6}\right]$ octahedron vs. $\mathrm{MeO}_{3}$ concentration. (b) Dependence of the $\mathrm{WO}_{6}$ distortion $\Delta$ from the valence state of tungsten. Solid line represents results from [7].
Table 1: Distortion $\Delta( \pm 0.001)$ of the first shell and its type in glasses and reference compounds from the EXAFS data. The attributed direction of the off-centre displacement is aiso given.

\begin{tabular}{l|c|c|c}
\hline \multicolumn{1}{c|}{ Compound } & $\begin{array}{c}\text { Type of } \\
\text { distortion }\end{array}$ & $\begin{array}{c}\text { Direction of } \\
\text { displacement }\end{array}$ & $\Delta(\AA)$ \\
\hline $\mathrm{CaWO}_{4}$ & 4 & & 0.045 \\
$\mathrm{Na}_{0.66} \mathrm{WO}_{3}$ & 6 & & 0.048 \\
$\mathrm{WO}_{3}$ & $4: 2$ & $\langle 110\rangle$ & 0.143 \\
$\mathrm{a}-\mathrm{WO}_{3}$ & $4: 1: 1$ & $\langle 110\rangle$ & 0.154 \\
$20 \% \mathrm{WO}_{3}$ & $3: 3$ & $\langle 111\rangle$ & 0.160 \\
$40 \% \mathrm{WO}_{3}$ & $3: 3$ & $\langle 111\rangle$ & 0.156 \\
$60 \% \mathrm{WO}_{3}$ & $3: 3(\sim 70 \%)$ & $\langle 111\rangle$ & 0.143 \\
$66 \% \mathrm{WO}_{3}$ & $2: 4$ & $\langle 110\rangle$ & \\
$\alpha-\mathrm{MoO}_{3}$ & $2: 2: 2$ & $\langle 110\rangle$ & 0.204 \\
$\beta-\mathrm{MoO}_{3}$ & $4: 2$ & $\langle 110\rangle$ & 0.171 \\
$\mathrm{a}-\mathrm{MoO}_{3} \# 1$ & $4: 1: 1$ & $\langle 110\rangle$ & 0.187 \\
$\mathrm{a}-\mathrm{MoO}_{3} \# 2$ & $4: 1: 1$ & $\langle 110\rangle$ & 0.184 \\
$10 \% \mathrm{MoO}_{3}$ & $3: 2: 1$ & $\langle 111\rangle$ & 0.181 \\
$20 \% \mathrm{MoO}_{3}$ & $3: 2: 1$ & $\langle 111\rangle$ & 0.176 \\
$40 \% \mathrm{MoO}_{3}$ & $3: 2: 1$ & $\langle 111\rangle$ & 0.172 \\
$60 \% \mathrm{MoO}_{3}$ & $3: 2: 1$ & $\langle 111\rangle$ & 0.164 \\
\hline & & & 0.145 \\
& $4: 20 \%)$ & & \\
\hline
\end{tabular}

In spite of the changes occurring within the first shell of metal ions in glasses, the peaks in FT's beyond the first one remain similar (see Figures $2(\mathrm{~b})$ and 3(b)): they are attributed mainly to the multiple-scattering (MS) effects within the first shell octahedron $[4,6]$. It is known that the MS contribution from an octahedron is less sensitive to its distortion than the single-scattering one [9]. At the same time, the MS contribution depends strongly on the photoelectron angular momentum (the absorption edge type), especially, in the case of the double-scattering paths $\mathrm{Me}_{0} \rightarrow \mathrm{O}_{1} \rightarrow \mathrm{O}_{2} \rightarrow \mathrm{Me}_{0}\left(\angle \mathrm{O}_{1} \mathrm{Me}_{0} \mathrm{O}_{2} \approx 90^{\circ}\right)$ within the first coordination shell whose contribution is smaller in the $\mathrm{K}, \mathrm{L}_{1}$-EXAFS than in $\mathrm{L}_{2,3}$-EXAFS $[9,10]$. These peculiarities of the MS signals explain the similarity of the peaks at $2.2-3.8 \AA$ in the same series of glasses and the difference between the peaks in FT's of tungsten and molybdenum glasses.

\section{Acknowledgments}

The authors are grateful to the staff of the ADONE PWA laboratory and the LURE DCI EXAFS-3 beam line for the support of the experiments. This work was supported in part by the International Science Foundation, Grants LF8000 and LJ8100.

\section{References}

[1] Selvaraj U. and Rao K.J., Chem. Phys. 123 (1988) 141-150.

[2] Bridge B. and Patel N.D., J. Mater. Sci. 21 (1986) 1187-1205.

[3] Studer F., Lebail A. and Raveau B., J. Solid State Chem. 63 (1986) 414-423.

[4] Balerna A., Bernieri E., Burattini E., Kuzmin A. and Purans J., "Study of the local environment around tungsten in mixed valence barium-tungsten-phosphate glasses by x-ray absorption spectroscopy", Proc. XVI International Congress on Glass, Madrid, 1992, vol. 3, pp. 347-352; Balerna A., Bernieri E., Burattini E., Kuzmin A. and Purans J., Preprint LNF-91/084 (IR) (Laboratori Nazjonali di Frascati, 1991) p.7.

[5] Kuzmin A., Physica B 208\&209 (1995) 174-175; Kuzmin A., J.Phys. IV France (contribution to this Proceedings).

[6] Kuzmin A and Purans J. , J. Non-Cryst. Solids (to be published).

[7] Domengès B., McGuire N.K. and O'Keeffe M., J. Solid State Chem. 56 (1985) 94-100.

[8] Cikmach P.D., Ph.D. Thesis (University of Latvia, Riga, 1985) pp.196-201 [in Russian].

[9] Kuzmin A. and Grisenti R., Phil. Mag. B 70 (1994) 1161-1175.

[10] Kuzmin A., Purans J., Benfatto M. and Natoli C.R., Phys. Rev. B 47 (1993) 2480-2486. 